\begin{tabular}{|c|c|}
\hline 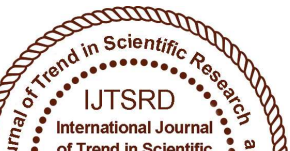 & $\begin{array}{l}\text { International Journal of Trend in Scientific } \\
\text { Research and Development (IJTSRD) }\end{array}$ \\
\hline $\begin{array}{lll} & \\
0\end{array}$ & International Open Access Journal \\
\hline and & ISSN No: $2456-6470$ | www.ijtsrd.com | Volume - 2 | Issue -3 \\
\hline
\end{tabular}

\title{
Experimental and numerical investigation on structural behaviour of Bubble Deck Slab with conventional slab
}

\author{
M. Ranjitham, N. V. Manjunath \\ Assistant Professor, Department of Civil Engineering, \\ Bannari Amman institute of technology, Erode, Tamilnadu, India
}

\section{ABSTRACT}

Slab is one of the largest consuming concrete member to carrying a load. A slab being the essential part of the building and should be successfully intended and utilized. The slab requires more concrete, while constructing the co2 emission is high and it leads to global warming, hence has to be optimized. Concrete plays a major role in the construction field. The usage of concrete is high in slab construction. Multiple elements transferring and resisting external loads throughout the structure. The vertical loads acting on the slab can be transferring to the beam and then column .The gravity path is depends upon the type of slab is used and also we consider the load transfers from the structure only on the column portion not throughout the slab. While reducing the dead weight of the slab the entire construction weight is least and cost saving is also elevated. Therefore we reduce the concrete in centre of the slab by using cast-off balls. Bubble Deck slab is one of the recently developed prefabrication construction technology functional in many engineering projects in the world. In Bubble Deck slab either can use steel balls or hollow balls will be recycled plastic and therefore it reduce the dead weight of the slab and also eliminating the concrete part which does not contribute to the structural concert. The model is analyzed by ANSYS software with appropriate support conditions as with the experimental setup and providing uniformly distributed loading in the bubble deck slab and in conventional slab. The stress and deformation results were evaluated and compared the bubble deck slab with conventional slab were observed using finite element analysis. At last the comparison has been made for Bubble Deck Slab with the Conventional slab over its self weight. From the evaluation of these

results, Bubble Deck Slab gives better performance than that of the conventional slab.

Keywords: Bubble deck slab, Conventional slab, Recycled plastic, Composite concrete and reinforcement concrete.

\section{INTRODUCTION}

In Denmark Bubble deck slab was invented and it has biaxial hollow core slab. Concrete is heavy material and the binding property is cement during manufacturing cement $10 \%$ of the world $\mathrm{Co}_{2}$ is created. USA proves that $20 \%$ faster construction with lesser formwork and simple installation of prefabricated bubble deck slab. Plastic recycled hollow balls give enough strength and non porous and also not react chemically with concrete or steel .It results light in weight less equipment is required. Bubble deck slab has easy incorporation of ducts and pipes into the slab after construction.

Decreasing the dead weight and increasing the efficiency of the floor and replaces the ineffective concrete in the middle of the slab by using high density polyethylene hollow spheres.

By introducing the voids leads to 35 to $55 \%$ lighter slab which minimise the loads on the column, foundations and walls.

The shear resistance will also be reduced due to reduced concrete volume. Compare to solid slab 0.6 times the shear resistance of bubble deck slab of same thickness. With same thickness compare to solid slab bending strength is also high 
Bending stresses are found to be $7 \%$ lower for Bubble deck. Low deflection value for strengthened bubble deck slab compare to conventional solid slab. $100 \mathrm{~mm}$ diameter size plastic ball is used. The recycled polyethylene hollow spheres are shown in Fig 1.

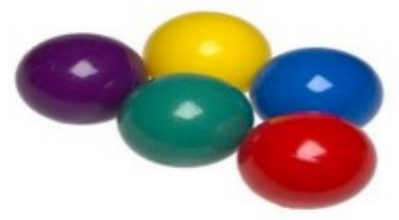

Fig 1 Recycled polyethylene hollow spheres

\section{B. STEEL REINFORCEMENT}

High grade steel of Fe 500 is generally used. The same grade of steel is used in both in top and bottom steel reinforcement. $10 \mathrm{~mm}$ diameter steel bar is used For main reinforcement $10 \mathrm{~mm}$ diameter steel bar is used and for distributor reinforcement $8 \mathrm{~mm}$ diameter steel bar is used

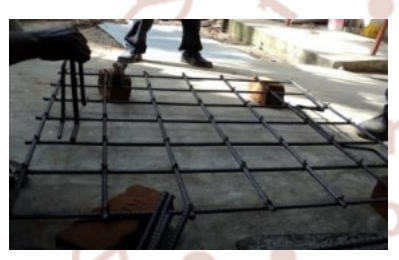

Fig 2 Reinforcements

\section{MATERIALS USED FOR CONSTRUCTION}

Ordinary Portland cement with well graded $12 \mathrm{~mm}$ diameter aggregates is used. Minimum grade of concrete M30 and M40 is used. The depth of the slab is about $200 \mathrm{~mm}$. The test were carried out according to the IS 456-2000 standard. The conventional concrete is shown in fig 3 .

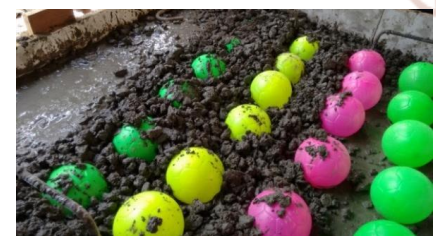

Fig 3 Concrete

Objectives of this project

1. The main purpose of this project is to replacing concrete with recycled polyethylene hollow spheres in rec slab

2. The structure is generally designed, using the conventional design methods for solid floor slabs \& bubble deck slab.
3. To investigate the mechanical characteristics of conventional slab \& bubble deck slab.

4. To compare the results of analytical and experimental

\section{NUMERICAL INVESTIGATION WITH ANSYS SOFTWARE}

In this project, the structural behaviour and strength of Bubble deck slab and Conventional slab are investigated using finite element software ANSYS. The finite element method is extensively used to study the behaviour of the structure such as shear strength, Equivalent stress, ultimate load, crack pattern, deflection at mid portion of slab for both Bubble deck slab and for Conventional slab.. The interconnected element may have different size and shape and connected at finite number of points called nodes. The test parameters included diameters of ball, slab thickness, width of the slab are feed into ANSYS.

\section{A. NUMERICAL MODELLING}

The Bubble deck slab and conventional slab are discretized using tetra hedral element type and it as 4 nodes and each node as 6 degree of freedom for concrete, steel reinforcement and for balls; it is suitable for both bubble deck slab and for conventional slab. Simply support, support conditions were provided for bubble deck slab and for conventional slab. Here, one end of support acts as hinge and other end of support which act as roller support. UDL load is applied for the area of about $500 \mathrm{~mm} \times 500 \mathrm{~mm}$ over the top portion of the slab. An axially compressive load was applied uniformly on the top surface of slab with displacement control.

The size of the slab is $750 \mathrm{~mm} \times 750 \mathrm{~mm} \times 200 \mathrm{~mm}$. The reinforcement details and model is drawn using AUTO CAD software for both bubble deck slab and for conventional slab and then it exported to ANSYS Workbench14.5 as 3D solid objects with identical geometry.

\section{B. NUMERICAL INVESTIGATION FOR BUBBLE DECK SLAB}

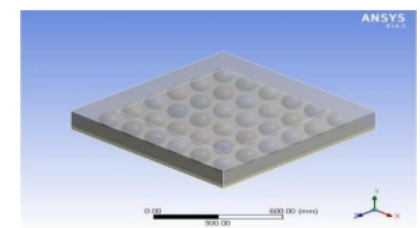

Figure 4 Modeling of Bubble Deck Slab 


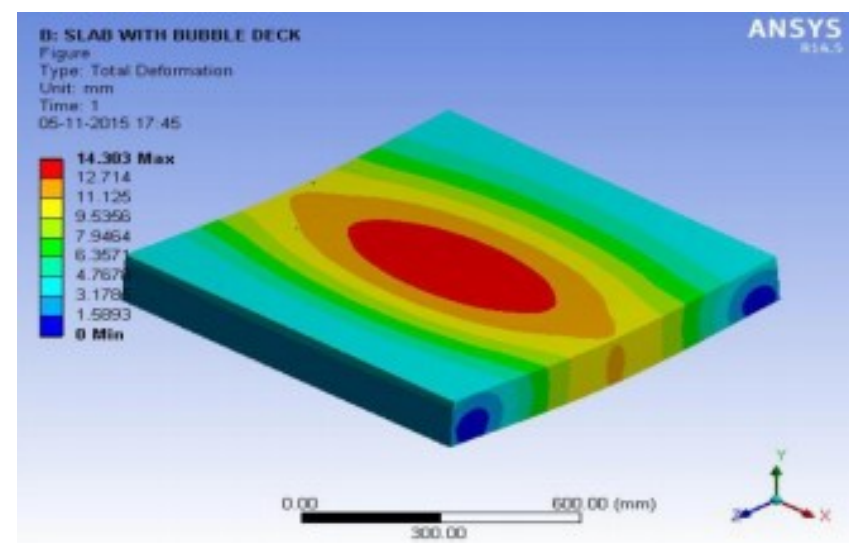

Figure 5 shows the behaviour of deflection of the bubble deck slab

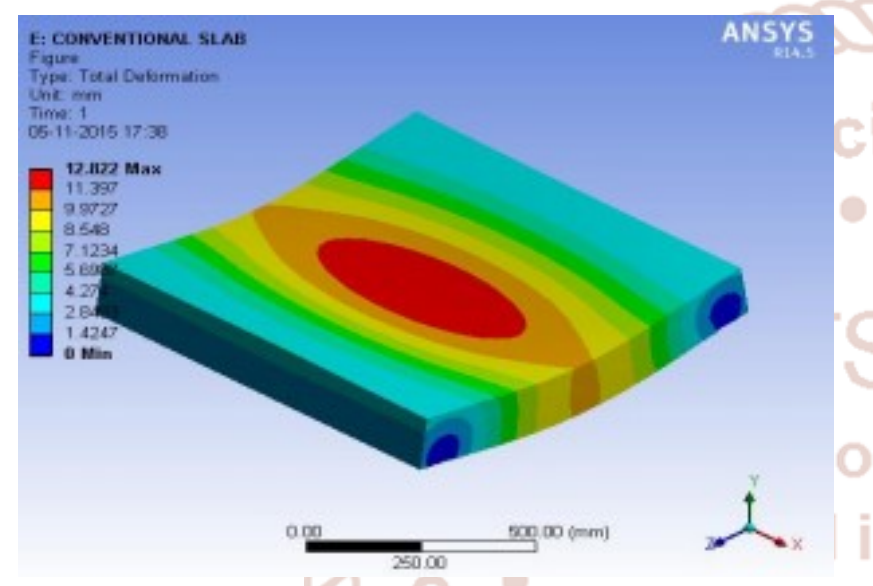

Figure 6 shows behaviour of deflection of Sear Conventional slab

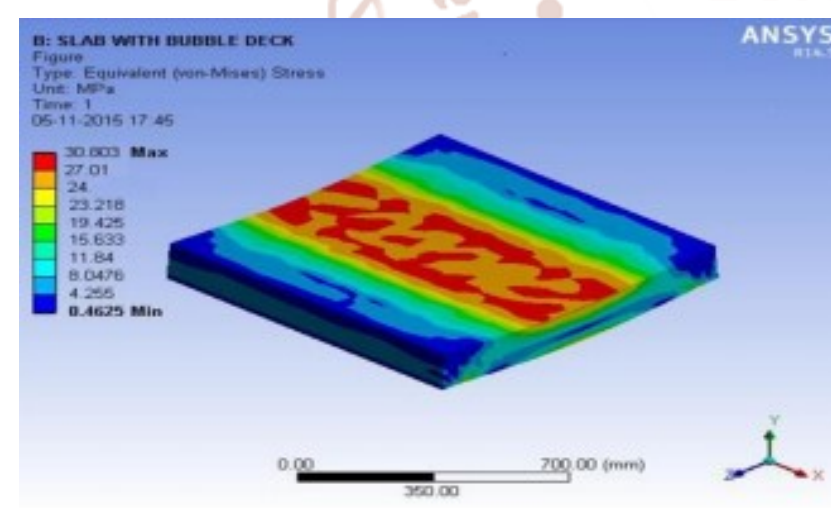

Figur e7 shows of Equivalent stress for bubble deck slab

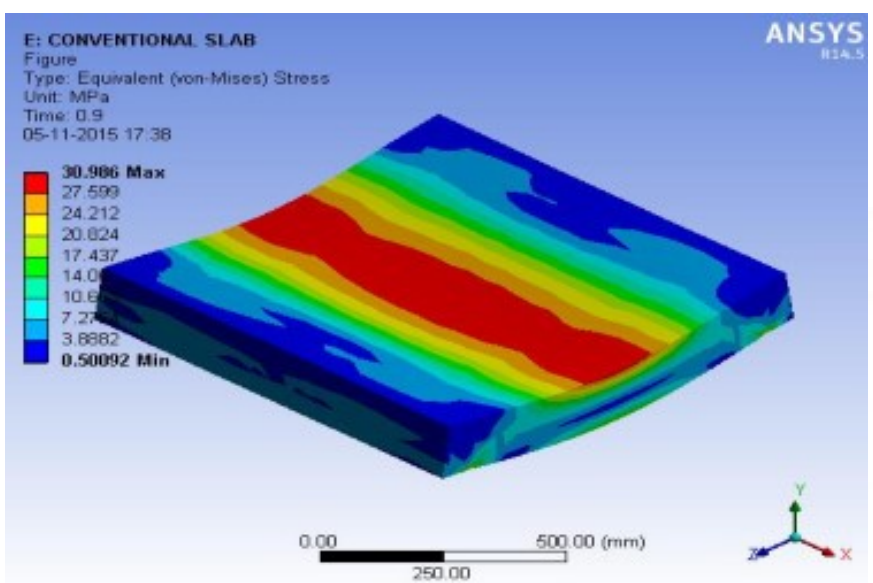

Figure 8 Equivalent stresses for Conventional slab

\section{III.EXPERIMENTAL INVESTIGATION}

A. Experimental procedure

Two type of specimens were casted, first one was a conventional one-way R.C slab and second one was one-way Bubble deck slab. The size of both slabs is $750 \mathrm{~mm}$ × $750 \mathrm{~mm} \times 200 \mathrm{~mm}$. The slab was simply supported at two sides which had a hinge support at one end and roller support at other end of slab.

Specimens were tested in Test Frame by applying Uniformly distributed load over the top portion of slab. The capacity of hydraulic jack IS maximum loading $500 \mathrm{KN}$.

Deflections were measured at mid span of the both Conventional slab and for Bubble deck slab and strain was measured using strain gauge. The load was increased gradually at increments of $10 \mathrm{KN}$ to record the deflection up to failure.

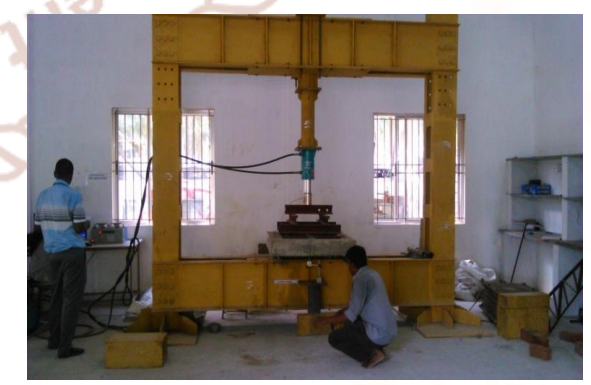

Figure 10 Testing in a loading frame 


\section{RESULT}

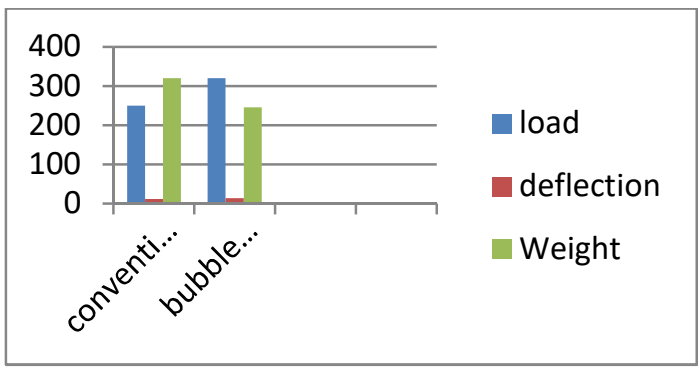

In that experiment found that volume of concrete the bubble deck (continuous) is reduced so that weight of slab ultimately decrease.

\begin{tabular}{|l|l|l|l|}
\hline $\begin{array}{l}\text { Type of } \\
\text { slab }\end{array}$ & $\begin{array}{l}\text { Load } \\
(\mathrm{Kn})\end{array}$ & $\begin{array}{l}\text { Deflecti } \\
\text { on(mm) }\end{array}$ & $\begin{array}{l}\text { Weight } \\
(\mathrm{Kg})\end{array}$ \\
\hline $\begin{array}{l}\text { Conventi } \\
\text { onal slab }\end{array}$ & 250 & 13 & 320 \\
\hline $\begin{array}{l}\text { Bubble } \\
\text { deck slab }\end{array}$ & 320 & 15 & 245 \\
\hline
\end{tabular}

Table no 1 comparison of results in experimental analyis

\section{CONCLUSION}

A. Weight reduction is $25 \%$ compared to solid slab.

B. The bubble deck technology is environmentally green and sustainable; avoiding the cement production allows reducing global $\mathrm{CO} 2$ emissions.

C. In comparative of conventional slab the volume of concrete in bubble deck (continuous) are less required, that is $25 \%$ approximately.

D. Simultaneously, bubble deck slab has improve the elasticity property of slab,

E. Cost and time saving by using bubbles in slab like weight of slab, concrete volume indirectly load on the beam and walls also decrease/ less so that building foundations is designed for smaller dead loads.

F. It is concluded that Load, deflection and weight parameters gives better result for bubble deck slab as compared to conventional slab.

G. Both in numerical and experimental results bubble deck slab shows a high load bearing capacity

\section{REFERENCES}

1) Arati Shetkarand \& Nagesh Hanche, "An Experimental Study On bubble deck slab system with elliptical balls", NCRIET2015 \&Indian J.Sci.Res. 12(1):021-027, 2015.

2) Harishma K.R and Reshmi K N, "A study on Bubble Deck slab", International Journal of Advanced Research Trends in Engineering and Technology (IJARTET) Vol. II, Special Issue X, March 2015.

3) Subramanian $K$ and Bhuvaneshwari $P$, "Finite Element Analysis of Voided Slab with High Density Polypropylene Void Formers", International Journal of Chem Tech Research, CODEN (USA): IJCRGG ISSN: 0974-4290, Vol.8, No.2, pp. 746-753, 2015.

4) Saifee Bhagat, Dr. K. B. Parikh, "Comparative Study of Voided Flat Plate Slab and Solid Flat Plate Slab", ISSN 2278 - 0211, Vol. 3 Issue 3, March, 2014.

5) A. Churakov Biaxial hollow slab with innovative types of voids, Saint-Petersburg Polytechnical University, 29 Polytechnicheskayast. St. Petersburg, 195251, Russia, ISSN 2304-6295.6 (21) 2014. 70-88. 8.

6) Amer M. Ibrahim, Nazar K. Ali, Wissam D. Salman "Flexural capacities of reinforced concrete two-way bubble deck slabs of plastic spherical voids" Diyala Journal of Engineering Sciences, ISSN 1999-8716, Vol. 06, No. 02, June 2013. 9. L. R. terec,

7) M. A. Terec The bubbledeck floor system: a brief presentation, CS I, INCD URBAN-INCERC Branch of Cluj-Napoca, CONSTRUCŢII - No. 2 / 2013. 10.

8) Wesley N. Mascarenhas Viscoelastic Analysis of Biaxial Hollow Deck Balls, International Journal of Computer Aided Engineering, ISSN: 10712317, Vol.23, Issue.1,(C) recent science publications archives, January 2013.

9) Gudmand-Hoyer T., "Note on the moment capacity in a Bubble Deck Joint", Rapport BYGDenmark Tekniske Universitet R-074, ISSN 16012917,ISBN 87-7877-136-6,2003.

10) Nielsen M., "Limit Analysis and Concrete Plasticicity", Second Editi on, CRC Press, 1998 